\title{
PREFERENCE FOR MAP SCALE OF IN-CAR ROUTE GUIDANCE AND NAVIGATION SYSTEM
}

\author{
Preferência por mapas em diferentes escalas para sistema de navegação e guia de \\ rota em automóvel
}

\author{
Ana Paula Marques Ramos ${ }^{1}$ \\ Mônica Modesta Santos Decanini² \\ Edmur Azevedo Pugliesi ${ }^{2}$ \\ Vilma Mayumi Tachibana ${ }^{2}$ \\ Renan Furlan De Oliveira² \\ Jader Mozella Marton Soares²
}

\begin{abstract}
1 Universidade do Oeste Paulista - UNOESTE. Mestrado em Meio Ambiente e Desenvolvimento Regional - MMADRE. Campus II, Rod. Raposo Tavares, km 572, Bairro do Limoeiro, CEP 19067-175 - Presidente Prudente - São Paulo. Brasil.Email:anaramos@unoeste.br

2 Universidade Estadual Paulista - UNESP, Faculdade de Ciências e Tecnologia. Rua Roberto Simonsen, 305, CEP 19060-900, Presidente Prudente - São Paulo. Brasil.Email:monca@fct.unesp.br; edmur@fct.unesp.br; vilma@fct.unesp.br; renanfurlanoliveira@hotmail.com; jadermozella@hotmail.com
\end{abstract}

\section{Resumo:}

A usabilidade dos mapas apresentados nos Sistemas de Navegação e Guia de Rota em Automóvel (SINGRA) pode resultar em sérios impactos na segurança no trânsito. Para a produção de SINGRA eficientes, a avaliação da satisfação do usuário tem consistido em um importante aspecto, uma vez que possibilitam os projetistas quantificarem a aceitação pela informação exibida no sistema. Um importante variável ao produzir mapas de SINGRA é a definição da escala. Um mapa em escala apropriada à demanda do motorista, por exemplo, à sua tarefa de navegação, pode auxiliá-lo a compreender rápido e facilmente a informação de navegação. Este trabalho avalia a preferência dos motoristas por mapas de SINGRA em diferentes escalas. Um total de 52 indivíduos participaram de um experimento simulado desenvolvido em um automóvel estacionado. Os mapas foram projetados em quatro diferentes escalas 1:1,000, 1:3,000, 1:6,000 e 1:10,000 para uma rota composta por 13 manobras. Para a produção dos mapas, aplicou-se os princípios da comunicação cartográfica, como agrupamento perceptivo, segregação de figura e fundo. De acordo com os casos estudados, conclui-se que os mapas nas escalas intermediárias $(1: 6,000$ e 1:3,000) foram os mais aceitos entre os motoristas, comparados aos mapas nas escalas maiores $(1: 1,000)$ e menores $(1: 10,000)$. As escalas dos mapas de SINGRA deveriam ser definidas para auxiliar o motorista a identificar rapidamente a direção da próxima manobra e, simultaneamente, obter informação sobre o contexto da rota por onde navega. Outros resultados são apresentados e suas implicações discutidas.

Palavras-chaves: Navegação em automóvel, usabilidade, preferência dos motoristas, mapas em diferentes escalas. 


\begin{abstract}
:
Usability issues of maps presented in-car Route Guidance and Navigation System (RGNS) may result in serious impacts on traffic safety. To obtain effective RGNS, evaluation of 'user satisfaction' with the system has played a prominent role, since designers can quantify drivers' acceptance about presented information. An important variable related to design of RGNS interfaces refers to select appropriate scale for maps, since it interferes on legibility of maps. Map with good legibility may support drivers comprehend information easily and take decisions during driving task quickly. This paper evaluates drivers' preference for scales used in maps of RGNS. A total of 52 subjects participated of an experiment performed in a parked car. Maps were designed at four different scales 1:1,000, 1:3,000, 1:6,000 and 1:10,000 for a route composed of 13 junctions. Map design was based on cartographic communication principles, such as perceptive grouping and figure-ground segregation. Based on studies cases, we conclude intermediate scales $(1: 6,000$ and 1:3,000) were more acceptable among drivers compared to large scales $(1: 1,000)$ and small $(1: 10,000)$. RGNS should select scales for maps which supports drivers to quickly identify direction of the maneuver and, simultaneously, get information about surroundings of route. More results are presented and implications discussed
\end{abstract}

Keywords: in-car navigation, usability, drivers' preference, maps at different scales.

\title{
1. Introduction
}

In recent decades, researchers in Human Computer Interaction (HCI) have become increasingly interested in the usability issues of maps presented by in-car Route Guidance and Navigation Systems (RGNSs) (Pugliesi et al. 2009; Ching-Torng et al. 2010; Ei-Wen Lo et al. 2011; Burnett et al. 2013; Ramos et al. 2014b). To receive information from the RGNS during driving, drivers must divert their eyes from the road, and this practice may have serious impacts on traffic safety (Wickens et al. 2004; Dalton et al. 2013). Thus, to reduce the risk of car accidents, RGNSs maps should offer high performance to both support drivers in navigation tasks and avoid visual distraction.

High-performance navigation maps could have important implications on usability of RGNSs (Pugliesi et al., 2009). Because drivers can easily comprehend information on a map, decisions can be made quickly during driving tasks (Lavie and Oron-Gilad 2013). Conversely, problems with cartographic communication presented by an interface could affect driver experience with the system (Pugliesi and Decanini 2009) and cause distraction on the road (Kaber et al. 2012).

To support drivers in navigation tasks and to improve the cartographic communication process between drivers and RGNSs, Marques et al. (2012) suggest that only relevant information should be presented on maps. This is because driving a car represents a hard task for drivers since they require processing several information simultaneously. Thus, when maps present exactly what drivers require in each part of journey it may be reduced drivers' mental overload. Additionally, Marques et al. (2012) suggest that the selected information should be shown as legibly as possible, and this means that the information selected for navigation maps should be presented according to cartographic principles to support communication between driver (the user) and map (the product). It is especially because this information is displayed on small screens from three to seven inches in dimension.

One of the most important variables noted by the literature in the design of RGNSs maps 
consists of the selection of the appropriate map scale (Uang and Hwang 2003; Li and Ho, 2004; Lee et al. 2008; Wu and Zhang 2009; Marques et al. 2012; Li et al. 2014; Ramos et al. 2014c; Ramos et al. 2014d). Scale is the variable that most significantly affects the legibility of a map because it determines the amount of information for the selected media to support a specific task (Dent et al. 2009; Slocum et al. 2009).

The use of RGNSs has exponentially grown over the last three decades. However, researchers have shown that these systems still use a large range of scales for their maps (Dillemuth et al. 2007; Ramos et al. 2014a). Moreover, these studies reveal that no guidelines exist to support the process of map scale selection. The scale chosen for RGNSs maps should provide visual balance for cartographic representations, which means avoidance of too much information or lack of information on the maps ( $\mathrm{Li}$ and Ho 2004; Marques et al. 2012). To achieve this visual balance for RGNSs maps, Marques et al. (2012) recommend adjusting the amount of information relative to the system display size and according to the different stages involved in the navigation task. Among these stages, a principal item of interest is related to tactical task, which refers to preparation for the next maneuver (Michon, 1985; Pugliesi et al. 2009).

Although the HCI literature has been traditionally focused almost exclusively on the effectiveness and efficiency of a system (Green et al. 1993; Liu 2001), the usability of RGNSs has been evaluated using both objective and subjective measures (Pugliesi et al. 2013). Currently, evaluation of 'user satisfaction' with the system plays a prominent role in the HCI research area (Pugliesi and Decanini 2009; Wakabayashi 2011; Ramos et al. 2014b). According to the International Organization for Standardization (ISO 9241-11 1998), 'user satisfaction' refers to one of three pillars of the usability evaluation process and is related to freedom from discomfort and a positive attitude toward the use of the product.

Pugliesi et al. (2013) argued that user satisfaction is an important measure for the development of RGNSs interfaces because it allows designers to quantify driver acceptance of information presented by these systems. These authors also note that questionnaires and interviews are necessary to collect data for subjective preferences and characterize these data-collection methods as easy, rapid, and low cost. Thus, driver preference for scales used in RGNSs maps could support map design decisions and consequently improve the RGNS usability.

This paper presents a preliminary study of driver preference for map scales used in In-car Route Guidance and Navigation Systems. The following questions are addressed: "Which scales are preferred by drivers for performance of navigation tasks supported by an RGNS?", "What type of information with respect to different scales is most important for drivers in making decisions?" and "Do relationships exist among driver preference and spatial ability, experience with in-car navigation systems, educational background or gender?".

\section{Method}

\subsection{Subjects}

A total of 52 subjects (26 males and 26 females), with ages between 20 and 38 years (mean $=26$, $\mathrm{SD}=4.4)$, participated voluntarily in this experiment. All participants were residents of Presidente Prudente town located in Sao Paulo state, Brazil. To recruit subjects, the following 
criteria were applied: valid driving license, regular driver for at least two previous years, and normal color vision. Subjects were divided into two equal-sized groups (group 1 and group 2) of 13 males and 13 females. Group 1 started the task using maps at 1:1,000 (maneuvers 1 to 3), after maps at 1:3,000 (maneuvers 4 to 6), after maps at 1:6,000 (maneuvers 7 to 10) and finished the task using maps at 1:10,000 scale (maneuvers 11 to 13). Group 2 started the task in a different sequence, first maps at 1:10,000 (maneuvers 1 to 3), then maps at 1:6,000 (maneuvers 4 to 6), after that maps at 1:3,000 (maneuvers 7 to 10) and then maps at 1:1,000 (maneuvers 11 to 13). It was adopted two different sequences to present the maps across different scales to counterbalance the potential order effects.

\subsection{Questionnaire and test of spatial ability}

A questionnaire was designed to collect individual characteristics from the participants, i.e., educational background and information on the frequency of use of an in-car navigation system. A four-point scale was adopted to collect data on frequency of use of RGNSs: frequently (every week), occasionally (once a month), rarely (once or twice a year) and never (never used the system).

Spatial ability was measured using the Santa Barbara Sense of Direction Scale (SBSODS) (Hegarty et al. 2002). This test consists of a 15-item survey that asks for agreement or disagreement with statements referring to orientation, navigation and map use via a seven-point scale. All participant responses were averaged for a single sense of direction score. Ethics Committee evaluated the procedures for human studies and allowed the current study development.

\subsection{Apparatus}

The experiment was performed during the day in a vehicle parked on the road. To enhance the driver's attention and comfort during the test, the vehicle was maintained with the engine running and the air conditioner turned on. A small-screen display (tablet Asus) was used as the navigational tool, more specifically, a seven-inch monitor set up for a 1024 x 768 pixel display. The small-screen display was placed in the vehicle dashboard on the right side of the steering wheel to represent the Head-Up Display (HUD) position. This location enhances performance for drivers who use in-car navigation systems (Wittmann et al. 2006).

The small-screen display was adopted to present the cartographic representations because although the maps for in-car navigation systems may be viewed on different platforms (smartphones, tablets, etc.), these systems commonly use small screens to present navigation information to drivers (e.g., screens smaller than seven inches). According to Li et al. (2014), one of the reasons refers to low cost of these small-screen displays and to be adequate to use inside vehicle. 


\subsection{Map scale selection}

Cartographic representations were designed at four different scales, i.e., 1:1,000, 1:3,000, 1:6,000 and 1:10,000. These scales were chosen based on a set of criteria, i.e., display size used to present maps, types of navigation tasks developed during the driving task and scales adopted for commercial RGNSs maps. The display size limits the amount of legible information that can be exhibited on the map (Dogru et al. 2009; Marques et al. 2012). Moreover, Burnett (1998) argues that drivers require different types of information in navigating along a route. Marques et al. (2012) adopted the display size and kind of navigation task as criteria to design automatic multi-scale maps for an RGNS prototype because these authors noted that map detail depends on the type of navigation tasks and media size and on which navigation information is presented.

Additionally, we assumed that the use of cartographic scales similar to those adopted for the commercial RGNSs maps would facilitate the study of driver satisfaction with the level of map detail presented by these systems to support navigation tasks. Thus we used the results presented by Ramos et al. (2014a) on map scales adopted for RGNSs maps commercialized in different countries (including Brazil) to select the scales for the cartographic representations in this work. However, it should be clear that the experiment would not measure the driver satisfaction for maps of commercial RGNS.

\subsection{Experimental route}

Navigation tasks occur in different cities of the world and on distinctive types of roads. To ensure that the cartographic representations showed a variety of types of urban roads, the set of criteria recommended by Pugliesi et al. (2009) was used to select the experimental route. These criteria included the traffic flow direction (one-way or two-way), the location of the roads (e.g., residential or central), the complexity of the maneuver (e.g., simple or complex) and the physical properties of the roads (width, length, etc.).

The experimental route is located in Alvares Machado town, which is situated next to Presidente Prudente. Subjects were able to participate of experiment only if they were not familiar with Alvares Machado city. It was imposed for drivers to avoid that the prior knowledge of the route interfered in the experiment results. The route is composed of 13 decision points throughout its $3.4 \mathrm{~km}$ length. These decision points were classified as simple or complex maneuvers. Simple maneuvers are decision points at which the driver is provided with the navigation choice of turning right or left (Pugliesi et al. 2009). Complex maneuvers are decision points at which the driver is provided with several navigation choices that could make the decision process more difficult (Labiale 2001; Pugliesi et al. 2009).

Roundabouts are an example of complex maneuvers because they contain multiple exits. The experimental route includes three roundabouts with multi-exits. The route was divided into four similar parts in such a manner that each part was represented with a different scale, as shown in Table 1. 
Table 1: Attributes of maneuvers in the experimental route and presentation order of scales for each driver group.

\begin{tabular}{|c|c|c|c|c|c|}
\hline $\begin{array}{l}\text { Maneuver } \\
\text { number }\end{array}$ & Decision point & $\begin{array}{l}\text { Navigation } \\
\text { guidance }\end{array}$ & $\begin{array}{l}\text { Complexity } \\
\text { of maneuver }\end{array}$ & $\begin{array}{c}\text { Scale } \\
\text { order- } \\
\text { driver } \\
\text { group } 1 \\
\end{array}$ & $\begin{array}{l}\text { Scale order - } \\
\text { driver group } 2\end{array}$ \\
\hline 1 & Intersection & Right turn & Simple & $1: 1,000$ & $1: 10,000$ \\
\hline 2 & Intersection & Left turn & Simple & $1: 1,000$ & $1: 10,000$ \\
\hline 3 & $\begin{array}{l}\text { Roundabout - } \\
\text { seven Choices }\end{array}$ & 4th exit & Complex & $1: 1,000$ & $1: 10,000$ \\
\hline 4 & Intersection & Right turn & Simple & $1: 1,000$ & $1: 10,000$ \\
\hline 5 & Intersection & Left turn & Simple & $1: 3,000$ & $1: 6,000$ \\
\hline 6 & $\begin{array}{l}\text { Roundabout - } \\
\text { five choices }\end{array}$ & 3rd exit & Complex & $1: 3,000$ & $1: 6,000$ \\
\hline 7 & Intersection & Right turn & Simple & $1: 3,000$ & $1: 6,000$ \\
\hline 8 & Intersection & Left turn & Simple & $1: 6,000$ & $1: 3,000$ \\
\hline 9 & Intersection & Right turn & Simple & $1: 6,000$ & $1: 3,000$ \\
\hline 10 & Intersection & Left turn & Simple & $1: 6,000$ & $1: 3,000$ \\
\hline 11 & Intersection & Right turn & Simple & $1: 10,000$ & $1: 1,000$ \\
\hline 12 & Intersection & $\begin{array}{l}\text { Right turn and } \\
\text { Immediately left } \\
\text { turn }\end{array}$ & Simple & $1: 10,000$ & $1: 1,000$ \\
\hline 13 & $\begin{array}{l}\text { Roundabout - } \\
\text { four choices }\end{array}$ & 2nd exit & Complex & $1: 10,000$ & $1: 1,000$ \\
\hline
\end{tabular}

\subsection{Cartographic representations}

To evaluate driver preference for the RGNS map scales, a set of cartographic representations were designed at four different scales $(1: 1,000,1: 3,000,1: 6,000$ and 1:10,000) to support the navigation tasks in an urban route. Representations at small scales were derived from an accurate cartographic database at a scale of $1: 1,000$ by applying generalization techniques. All cartographic representations were constructed using ESRI ArcGIS software. Figure 1, Figure 2 and Figure 3 show the set of representations which the first (Figure 1 and Figure 2) and the second group (Figure 3) group of drivers saw respectively. We adopted two different sequences to present representations across four scales to counterbalance the potential order effects.

To design cartographic representations at different scales, we applied seven fundamental operations of generalization: selection, collapse, exaggeration, displacement, aggregation, symbolization and abbreviation. The information elements selected for cartographic representations at different scales are car $(\mathrm{RGB}=255,0,0)$, route $(\mathrm{RGB}=0,0,0)$, direction arrow $(\mathrm{RGB}=0,255,0)$, railroad $(\mathrm{RGB}=230,0,200)$, street name $(\mathrm{RGB}=0,0,0)$, and road network. Roads were divided into main $(\mathrm{RGB}=255,166,0)$ and secondary ( $\mathrm{RGB}=255,255,255)$ roads. According to the literature review, this set of elements represents the most important map elements used to support drivers in navigation tasks (Burnett 1998; May et al. 2003). 
The collapse operation was applied to represent the road network (e.g., Figure 3a). The collapse of a road into a single line at smaller scales allowed reduction of the amount of detail displayed on maps at scales of 1:6,000 and 1:10,000. Exaggeration is one of the more commonly applied generalization operations in which the aim is to amplify a specific component of an object to maintain clarity in the scale reduction (Slocum et al., 2009). The exaggeration operation was applied to represent the route element. A route consists of several segments that the driver will traverse during a journey (Lee et al., 2008). Thus, exaggeration of the route size on the map might allow drivers to more easily identify their locations in the road network.

The displacement operation was applied on a railroad element to separate it from the route when represented at scales of 1:6,000 (e.g., Figure 3f) and 1:10,000 (e.g., Figure 3d). The railroad was selected in the RGNS maps to provide spatial context for drivers. The displacement operation is used to counteract problems that arise when two or more map elements are in conflict due to proximity, overlap or coincidence (Shea and McMaster, 1992).

The direction arrow on RGNS maps intended to highlight the maneuver direction to aid drivers in understanding how to travel in the correct direction (Pugliesi et al. 2009). On the experimental route, if maneuvers were located close each other, coalescence between direction arrows occurred in the scale reduction. Shea and McMaster (1992) argue that many instances occur in which the density of points within a region prohibits symbolizing them individually within a map. Thus, to maintain the legibility of the map, the aggregation operation was applied to represent the direction arrow (e.g., Figure 3b). Because this operator involves the merging of multiple point features (Slocum et al. 2009), two direction arrows were merged into only one direction arrow.

The symbolization operation was applied after application of the collapse and aggregation operations. Additionally, the symbolization operator was applied as an independent operator to represent the arrow direction in the scale reduction. Figure $2 \mathrm{f}$ exemplifies a direction arrow before application of the symbolization operation, and Figure $3 \mathrm{e}$ shows the result.

Finally, the abbreviation operation was applied to label the street names on maps exhibited across four different scales. The results of this application are shown in Figures 1g, 11, 2c and 2f. It must be noted that other street names are omitted on maps if they are not labeled as main roads or secondary roads directly linked to the chosen route.

To minimize the effect of design choices (information selection and symbolization) and to ensure that the main effect evaluated in the experimental procedure is the map scale, the cartographic representations were designed to display not only a consistent level of information across the four scales but also an equivalent map design across the variation of map scales. The map design was based on perceptive grouping and figure-ground segregation as noted by MacEachren (1995), Dent et al. (2009) and Slocum et al. (2009) for cartographic communication principles that should be considered in the design of maps. Additionally, driver preference for the color of the route and direction arrow were considered and adopted in the RGNS maps (Ramos et al. 2014b).

Cartographic representations were presented in heads-up orientation (egocentric view) and orthogonal view (2D maps) similar to the RGNS prototype developed by Marques et al. (2012). Navigation system manufacturers often allow drivers to choose between navigation displays with an orthogonal view (2D map) or a perspective view (3D map). Lin et al. (2010) argue that the 3D representations of RGNSs developed by the industry require much more improvement to the map design for better efficacy.

Cartographic representations presented using the orthogonal view depict the car reaching the decision point 100 meters before the next maneuver. This distance was chosen to represent the 
tactical task according to previous work (Pugliesi et al. 2009; Marques et al. 2012). Although the navigation task involves different stages, we decide to simulate only the tactical task in this work because it is considered the most critical stage in navigation tasks. Because the tactical task consists of preparing to perform the maneuver (Michon 1985), it could overload the driver's cognitive and perceptive processing systems (Kaber et al. 2012).

To indicate the beginning of a tactical task in the navigation task, a beep was generated by the tablet's audio system. A total of 13 beeps were presented along the route, one before each maneuver. To simulate the car moving along the route, a set of cartographic representations was presented using Microsoft PowerPoint software. Each map along the route was shown for a duration of five seconds. This approach has been used in other studies related to the usability of in-car navigation systems, e.g., Pugliesi and Decanini (2009) and Ramos et al. (2014b).

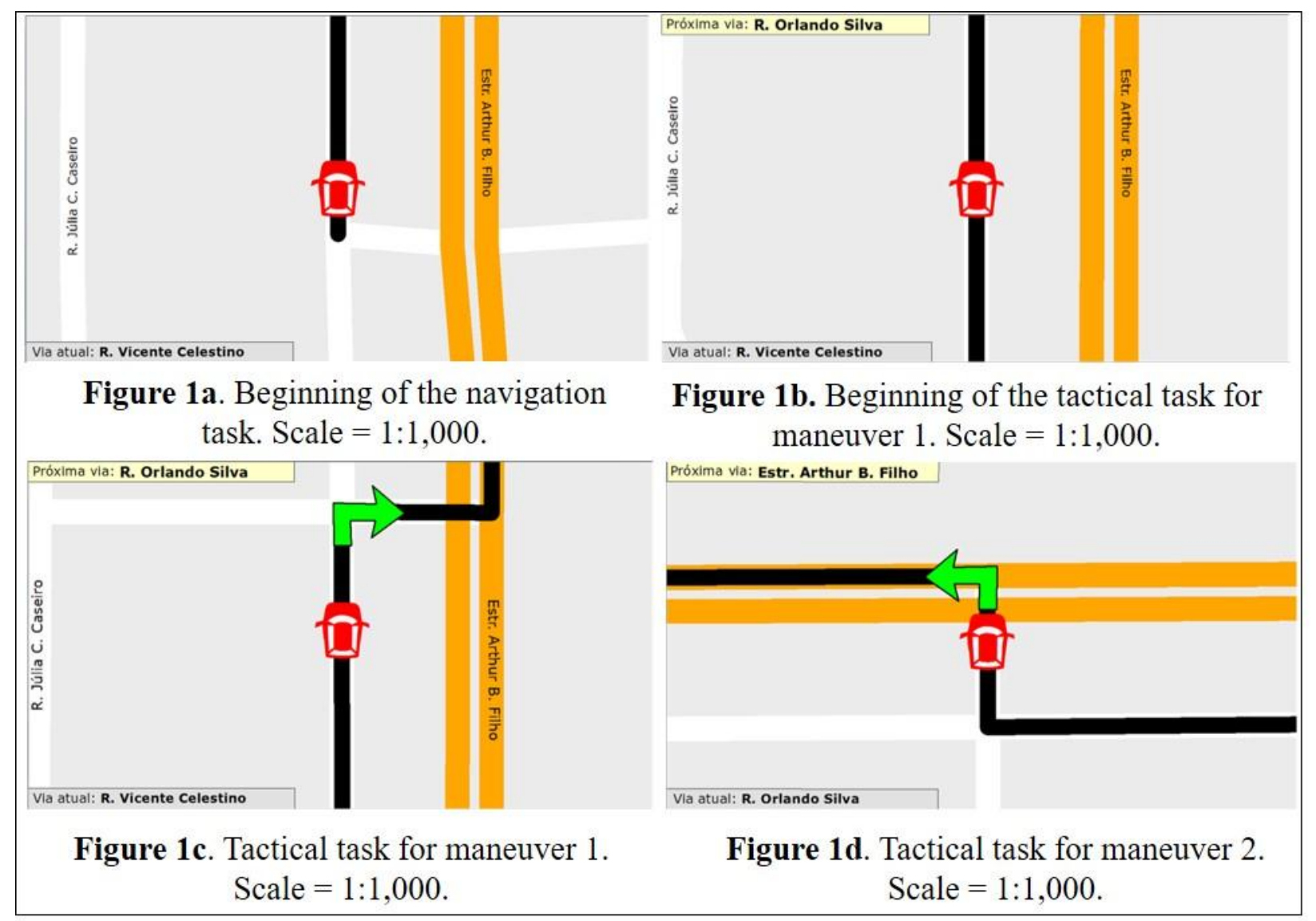

Figure 1: Representations from the first through sixth maneuvers presented to the first group of drivers, as shown in Table 1. 


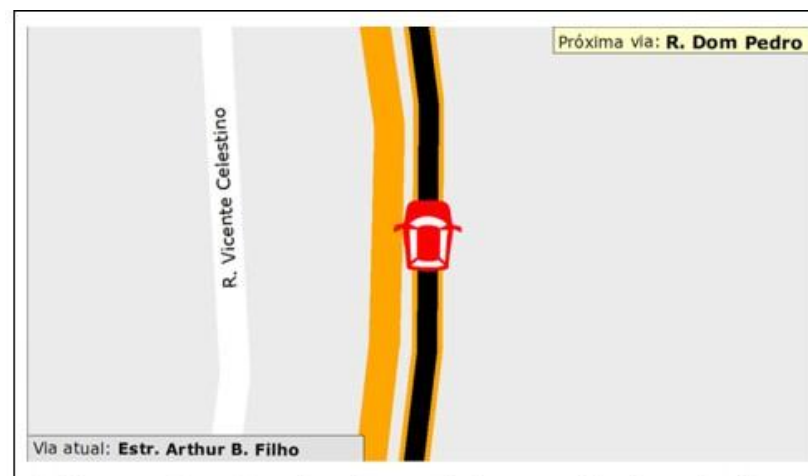

Figure 2a. Beginning of the tactical task for maneuver 3. Scale $=1: 1,000$.

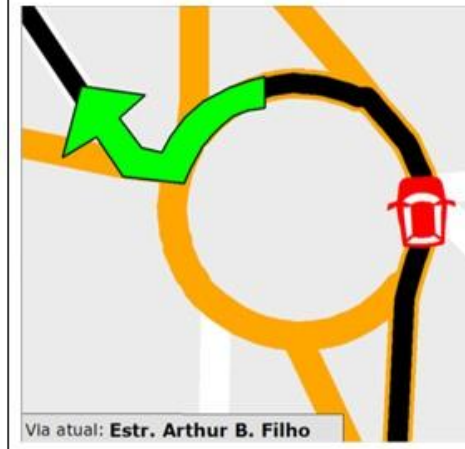

Próxima via: R. Dom Pedro I

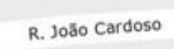

Figure 2c. Maneuvering at the third turn. Scale $=1: 1,000$.

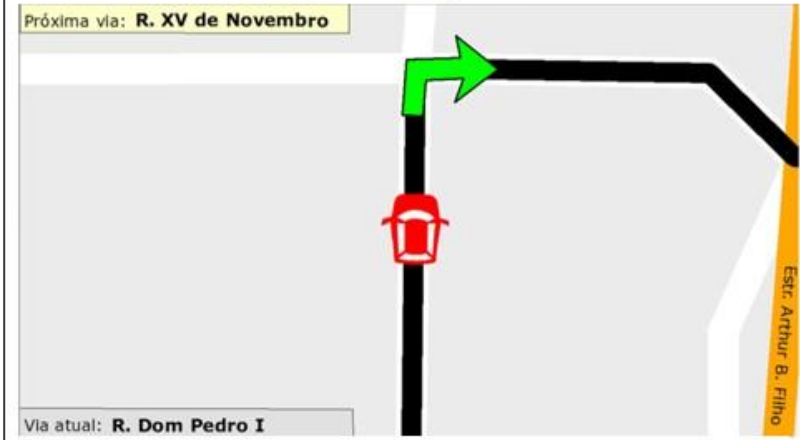

Figure 2e. Tactical task for maneuver 4. Scale $=1: 1,000$.

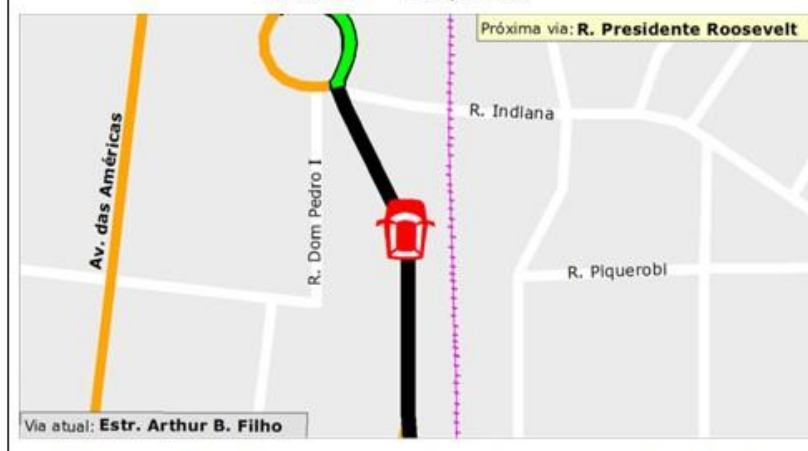

Figure 2g. Beginning of the tactical task for maneuver 6. Scale $=1: 3,000$.

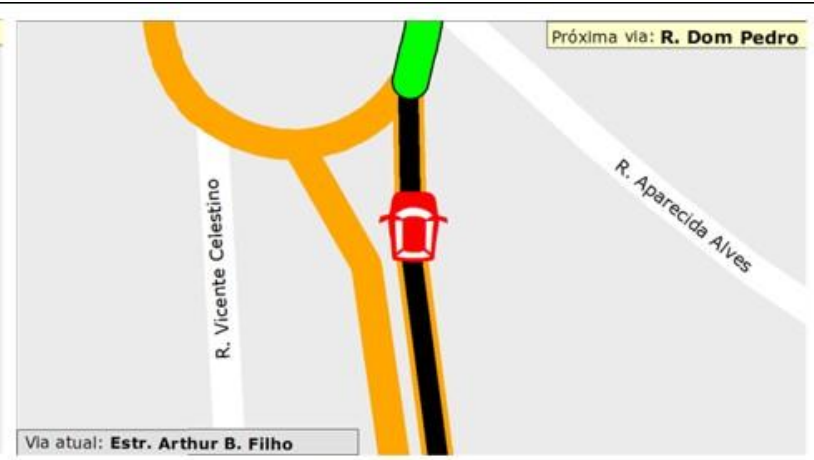

Figure 2b. Tactical task for maneuver 3 . Scale $=1: 1,000$.

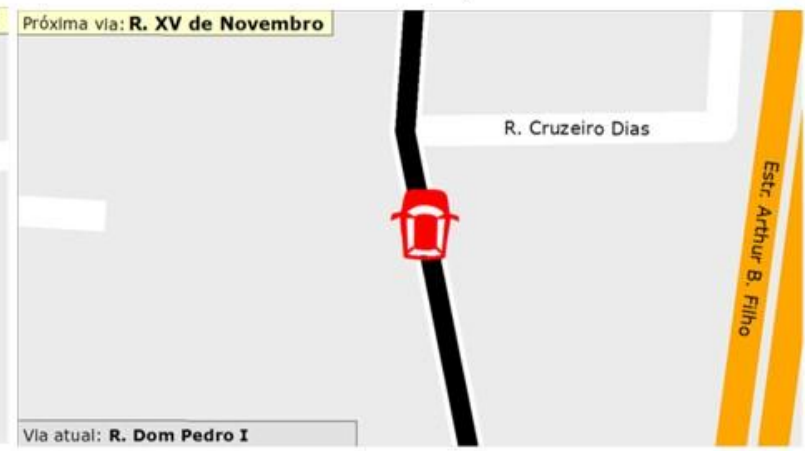

Figure 2d. Beginning of the tactical task for maneuver 4. Scale $=1: 1,000$.

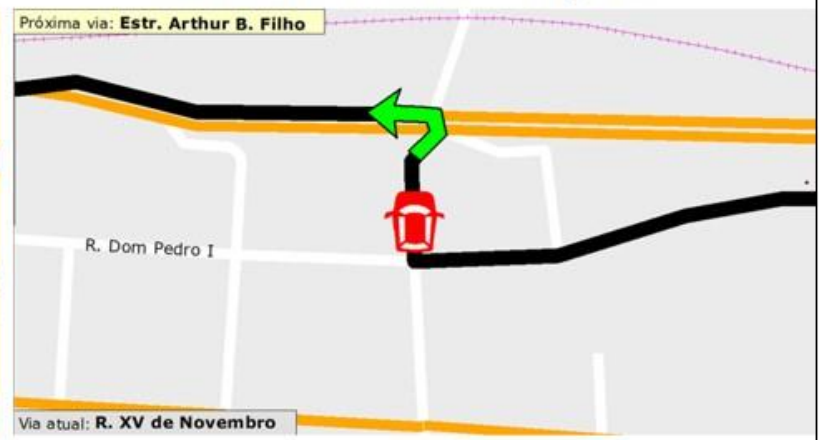

Figure 2f. Beginning of the tactical task for maneuver 5. Scale $=1: 3,000$.

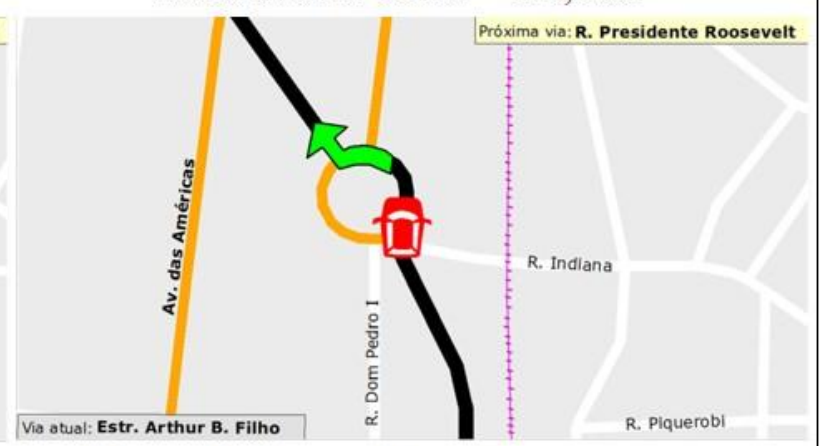

Figure 2h. Tactical task for maneuver 6. Scale $=1: 3,000$.

Figure 2: Representations from the first through sixth maneuvers presented to the first group of drivers, as shown in Table 1 


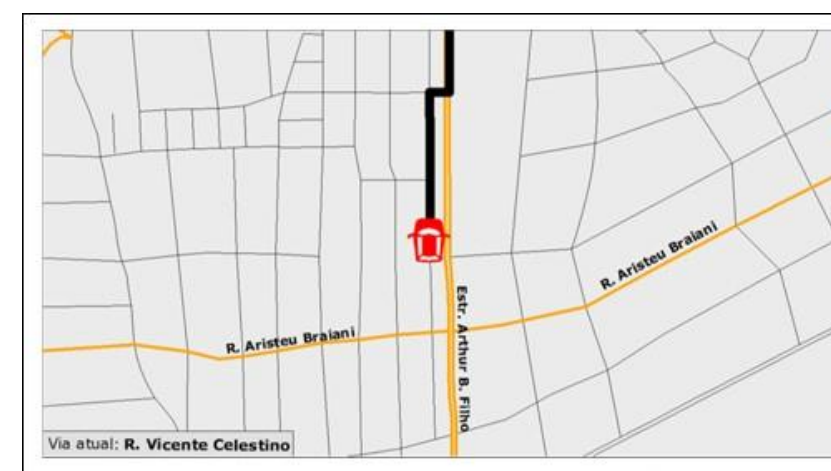

Figure 3a. Beginning of the navigation task. Scale $=1: 10,000$.
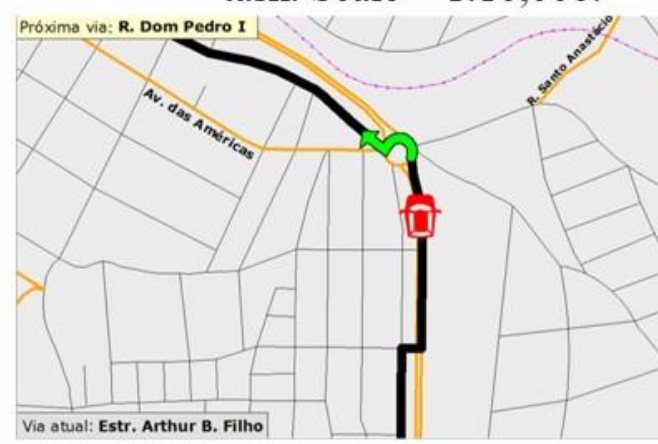

Figure 3c. Beginning of the navigation task for maneuver 3. Scale $=1: 10,000$.

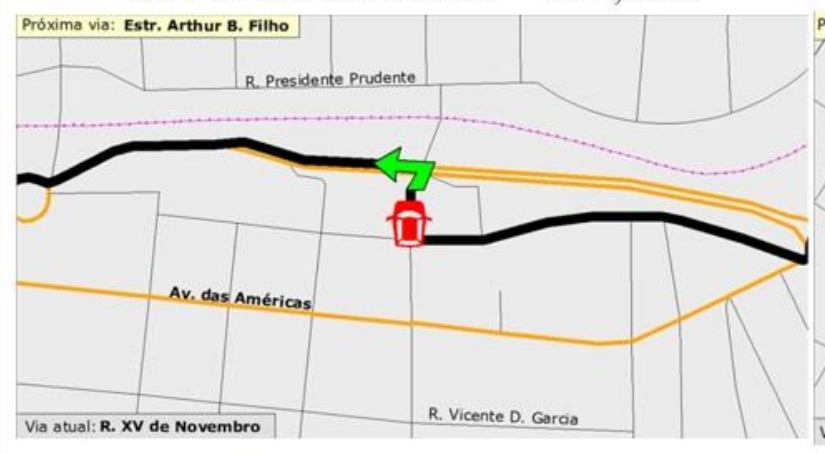

Figure 3e. Beginning of the tactical task for maneuver 5. Scale $=1: 6,000$.

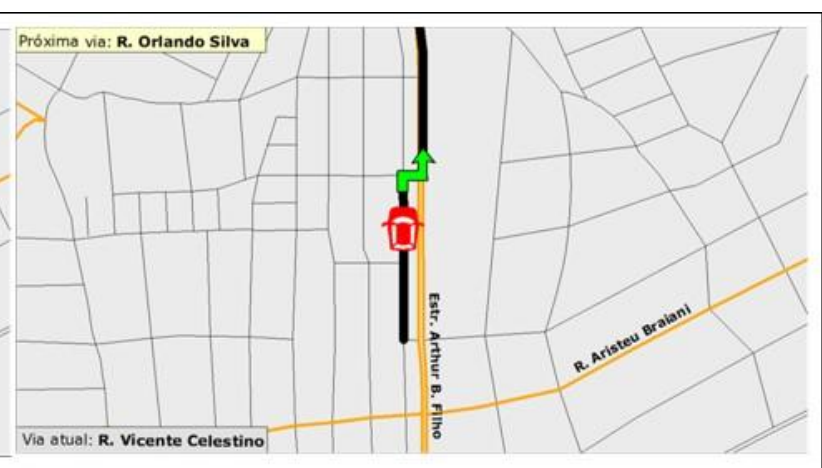

Figure 3b. Beginning of the tactical task for maneuvers 1 and 2. Scale $=1: 10,000$.

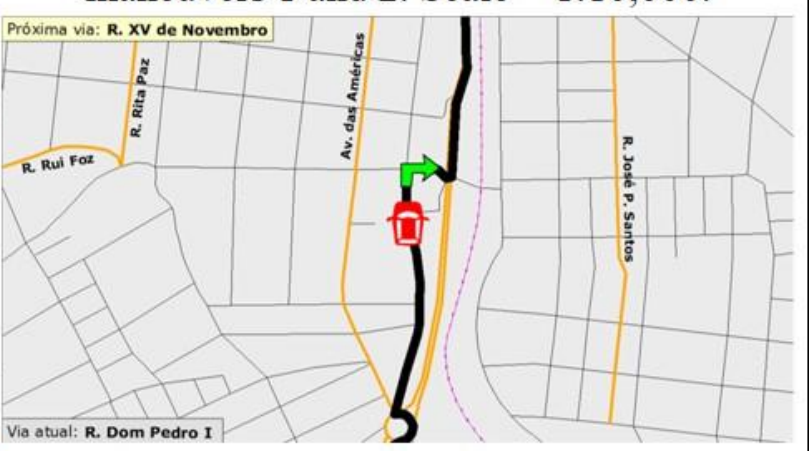

Figure 3d. Beginning of the tactical task at maneuver 4. Scale $=1: 10,000$.

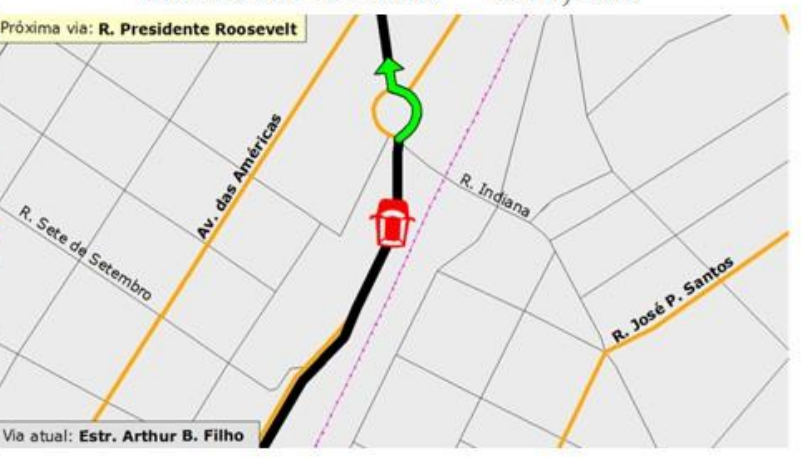

Figure 3f. Beginning of the tactical task for maneuver 6 . Scale $=1: 6,000$.

Figure 3: Representations of the first through sixth maneuvers presented to the second group of drivers, as shown in Table 1.

\subsection{Procedure}

The experiment was applied individually and took 20 minutes to complete. First, drivers entered the car, and the experimenter explained the purpose of the test. Next, drivers completed the questionnaire for individual characterization and the spatial ability test (SBSODS). Drivers were asked to sign a consent form before the experiment began. To familiarize drivers with the beep and the scales selected for the cartographic representations, the experimenter explained how the beep worked and presented examples using certain visual maps with different scales. 
Before beginning the simulation, drivers were asked to assume that they would be taking a journey by car in an unknown town using an RGNS that presents maps at different scales. Drivers were also instructed to assume that they were driving, and thus, they should pay close attention to the road. To increase driver attention to the test, after hearing the beep, drivers were instructed to verbalize the maneuver direction as understood from the map. Finally, to simulate the journey, the experimenter presented the cartographic representations to the driver for five seconds each to simulate the car motion along the route.

After finishing the simulation, the experimenter asked the following question: "Among the scales shown $(1: 1,000,1: 3,000,1: 6,000$ and 1:10,000), what would be your order of preference, from first to fourth, for a navigation task using the RGNS and why?" Asking for drivers to justify the reason for scale choice was important to identify the scales that might have the potential to improve legibility of RGNS maps according to maneuver complexity. All driver preferences and opinions were collected using an audio recorder and questionnaire.

\subsection{Dependent and independent variable and Statistical analysis}

The dependent variable is related to the preference for four map scales. The independent variables are the factors related to the subject's group and individual characteristics, i.e., spatial ability, experience with RGNS and educational background. Gender was taken as a group characteristic.

Data were processed using SPSS 16.0 (Statistical Package for the Social Sciences Software) and a confidence level of $95 \%$ (significance level less than or equal to .05). According to the distribution of the data, either parametric (2-sample T-test) or nonparametric analysis (chisquared test $-\chi 2$, Friedman test $-\chi 2 \mathrm{r}$ or Cochran's Q test) was used as recommended by Conover (1999). The Kolmogorov-Smirnov Z-test indicated that only the spatial ability data presented a normal probability distribution $(\mathrm{p}=0.2)$.

\section{Results}

\subsection{Map scale preference}

A comparison among maps was conducted to identify the order of preference for the four different scales of 1:1,000, 1:3,000, 1:6,000 and 1:10,000. As shown in Figure 4, maps at the 1:6,000 scale were the most preferred for support of in-car navigation tasks. According to the drivers' comments, maps at this scale helped them to quickly and easily identify the direction to take for each maneuver.

In the second place, the maps at 1:3,000 and 1:6,000 scales were the two most preferred among drivers (Figure 4). The least preferred map was at 1:1,000, occupying the fourth place for more than $90 \%$ of drivers. These results suggest that, to perform the navigation task, drivers preferred map scales in the following order 1:6,000, 1:3,000, 1:10,000 and 1:1,000. To corroborated that 
this order of preference by navigation maps is not random, the Friedman test was applied and the results $(\chi 2 \mathrm{r}=104.15, \mathrm{p}<0.0001)$ could be confirmed.

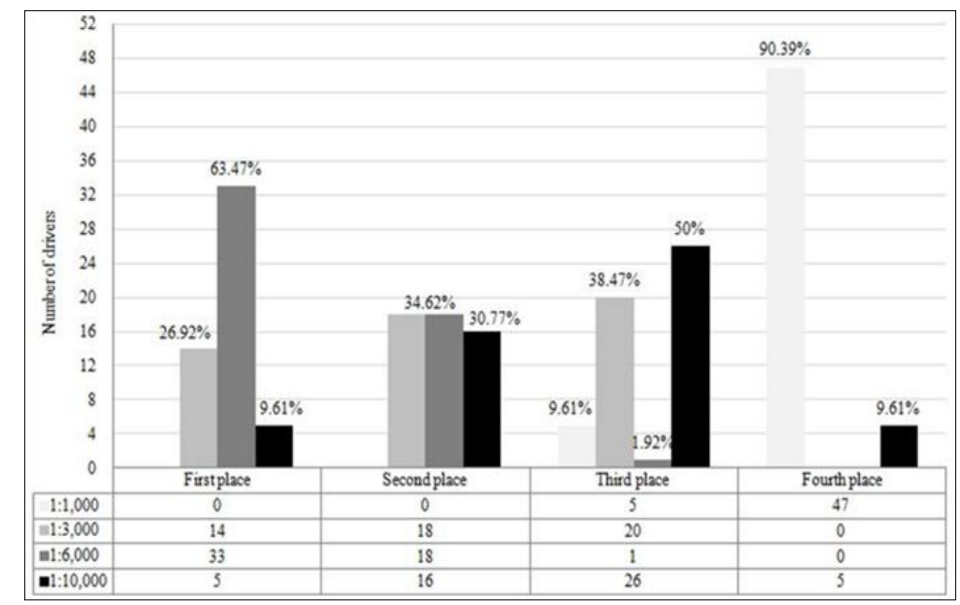

Figure 4: Order of preference for the four different map scales.

\subsection{Individual characteristics}

Considering all 52 subjects, the mean score obtained for spatial ability was 4.175 ( $\mathrm{SD}=0.46$ ). The 2-sample test was conducted to compare the mean score between two groups of drivers (group $1 \mathrm{x}$ group 2). The results did not reveal a significant difference $(\mathrm{t}=1.169 ; \mathrm{p}=0.248)$, which indicates that both groups had quite similar spatial abilities. Thus, this result implied that the results of subjective preference for map scales are not dependent on differences in spatial ability.

The results from the 2-sample test also showed that the drivers' spatial ability was not related to either their gender $(t=0.743 ; \mathrm{p}=0.461)$ or educational background $(\mathrm{t}=-0.610 ; \mathrm{p}=0.545)$. However, this test $(\mathrm{t}=2.469 ; \mathrm{p}=0.017)$ suggested that drivers who frequently or occasionally use navigation systems displayed higher spatial ability scores than those who rarely or never used this type of system. Educational background was divided into two classes: A (32) and B (20). Class A was composed of subjects who had professional skills in map making, i.e., survey engineer, environmental engineer, geographer, architect and geologist, and class B was composed of subjects with no professional background in map making.

To verify the relationship between subjective preference for map scales and driver gender or individual characteristics, the Chi-square test was performed. The comparisons showed no significant relationship between those factors and the map scale $(p>0.05)$. Thus, this result implies that gender $(\chi 2=2.073, \mathrm{p}<0.355)$, educational background $(\chi 2=2.551, \mathrm{p}<0.279)$, spatial ability $(\chi 2=1.198, \mathrm{p}<0.549)$ and experience with navigation system $(\chi 2=0.755, \mathrm{p}<0.685)$ had no effect on the drivers' preference for the scales.

\subsection{Information categories for maps of in-car navigation systems}

The opinions provided by the 52 participants on each cartographic scale were analyzed in detail. Each type of navigation information provided to the drivers was classified into five different information categories (Table 2): 'Direction of the next maneuver (DNM)', 'Current location on the route (CLR)', 'Distance remaining until the next maneuver (DRM)', 'Information on the next 
maneuvers (INM)', and 'Information on general surroundings of the route (IGS)'. These categories were defined based on the categorization scheme proposed by Burnett (1998) and May et al. (2003).

The use of these five categories allowed us to understand the 'context of driving' for the drivers and to identify what type of navigation information they require from RGNS maps. According to Dey (2001), 'context of driving' refers to the information from the environment that is most important to drivers in navigation. Table 2 presents the categorized navigation information and examples of comments provided by the drivers.

Table 2. Information categories and examples of comments provided by drivers.

\begin{tabular}{l|l|l}
\hline \multicolumn{1}{c|}{$\begin{array}{c}\text { Information } \\
\text { category }\end{array}$} & \multicolumn{1}{c}{ Description } & \multicolumn{1}{c}{ Examples of driver comments } \\
\hline DNM & $\begin{array}{l}\text { Direction of the next } \\
\text { maneuver }\end{array}$ & $\begin{array}{l}\text { "Shows the next maneuver well." } \\
\text { "Clearly informs me where I should turn." }\end{array}$ \\
\hline CLR & $\begin{array}{l}\text { Current location on } \\
\text { the route }\end{array}$ & $\begin{array}{l}\text { "It is easy to find where I am on the route at this scale." } \\
\text { "I quickly recognize what street the vehicle is on." }\end{array}$ \\
\hline DRM & $\begin{array}{l}\text { Distance remaining } \\
\text { until next maneuver }\end{array}$ & $\begin{array}{l}\text { "Shows upcoming maneuver in advance." } \\
\text { "Easy to identify the distance to the next maneuver." }\end{array}$ \\
\hline IGS & $\begin{array}{l}\text { Information on the } \\
\text { next maneuvers }\end{array}$ & $\begin{array}{l}\text { "I can see the following maneuvers." } \\
\text { "Helps to see details of the 2nd and 3rd following maneuvers." }\end{array}$ \\
\hline
\end{tabular}

In this stage of work, two analyses were carried out. The first analysis was conducted to understand the intra-category relationships, i.e., to identify the types of information that were more frequently mentioned by drivers independent of the chosen scale. The second analysis was conducted to understand the relationship between the information categories and the scales. Figure 5a shows that 'Direction of the next maneuver' (DNM) and 'Information on general surroundings of the route' (IGS) were the two categories with the highest frequency of use, and Cochran's test revealed that these results were significant $(Q=97.97, p<0.0001)$.

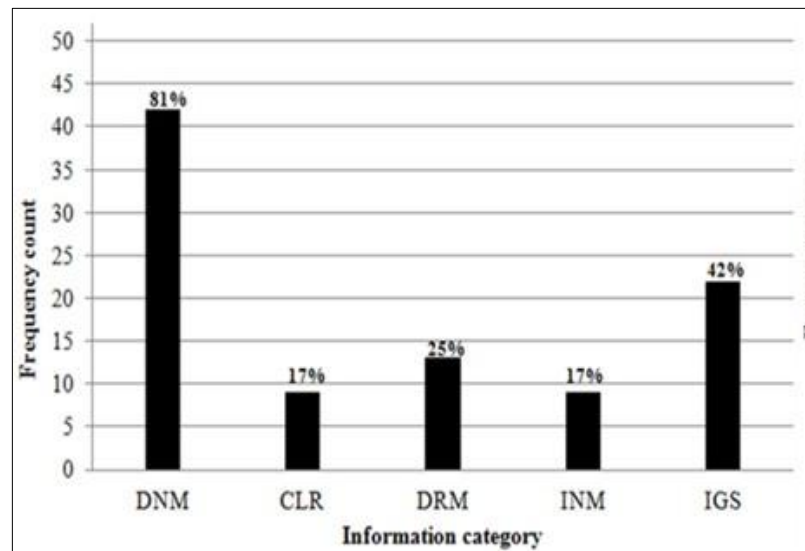

(a)

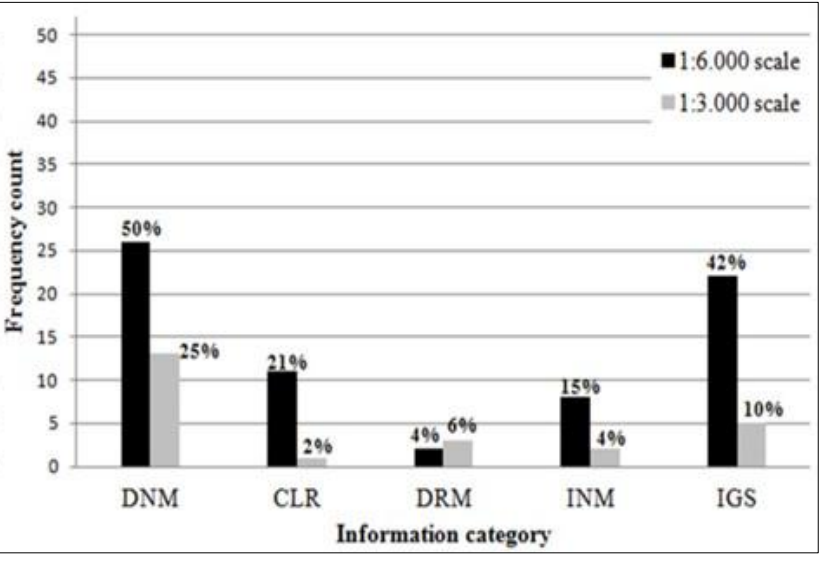

(b)

Figure 5: Information categories reported by all 52 participants (a), and information categories reported by participants who preferred maps at the $1: 6,000$ or 1:3,000 scale (b). 
The second analysis determined the most frequent categories used to explain preference for the 1:6,000 and 1:3,000 scales. For those drivers who selected 1:6,000 as the preferable map scale, DNM and IGS are the most frequently mentioned categories (Figure 5b). For those drivers who selected 1:3,000, the highest frequency occurred for the DNM category. The use of these information categories was significant for $1: 6,000(\mathrm{Q}=72.08, \mathrm{p}<0.0001)$ and $1: 3,000(\mathrm{Q}=97.61$, $\mathrm{p}<0.0001$ ), as indicated by Cochran's test.

The lowest preference for 1:1,000 was justified due to the lack of DNM (67\%), IGS (46\%) and DRM (44\%) information. Moreover, the driver comments for maps at the 1:10,000 scale primarily concentrated on the DNM and CLR categories. Positive and negative driver comments on the four scales adopted in this work are shown in Table 3.

Table 3: Driver comments on the map scales.

\begin{tabular}{|c|c|c|}
\hline Scale & Positive comments & Negative comments \\
\hline $1: 1,000$ & $\begin{array}{l}\text { "I prefer to see specific details of the } \\
\text { roundabout." } \\
\text { "I can identify the exit of the roundabout." }\end{array}$ & $\begin{array}{l}\text { "I can visualize the maneuver very closely". } \\
\text { "It does not offer me enough information for I am } \\
\text { on the route." }\end{array}$ \\
\hline $1: 3,000$ & $\begin{array}{l}\text { "It is easy to recognize the distance to the next } \\
\text { maneuver." } \\
\text { "Better information on the maneuver } \\
\text { direction." }\end{array}$ & $\begin{array}{l}\text { "I cannot analyze the elements near the route." } \\
\text { "I can only visualize the next maneuver." }\end{array}$ \\
\hline $1: 6,000$ & $\begin{array}{l}\text { "It shows a general view of the route and I can } \\
\text { find my position on it easily" } \\
\text { "I can visualize the following maneuvers." }\end{array}$ & "It does not describe the roundabout in detail." \\
\hline $1: 10,000$ & $\begin{array}{l}\text { "It offers spatial context and it helps me to find } \\
\text { alternative routes." } \\
\text { "I can visualize segments of the route after the } \\
\text { performed maneuver." }\end{array}$ & $\begin{array}{l}\text { "It presents several road names; too much } \\
\text { information on the map". } \\
\text { "Although I can visualize two or more following } \\
\text { maneuvers, the next maneuver lacks detail". }\end{array}$ \\
\hline
\end{tabular}




\section{Discussion}

The results of the experimental procedure revealed that driver preference for map scale is not random. Drivers preferred to visualize maps at 1:6,000 to perform in-car navigation tasks using an RGNS. According to their comments, the 1:6,000 scale is correct for RGNS maps because it supports identification of the direction of the next and subsequent maneuvers and supplies information on the surroundings along the route. These results imply that a navigation map at the 1:6,000 scale establishes a proper relationship between the spatial information along the route and the details of the maneuver directions.

Considering the model proposed by Ross and Burnett (2001) in terms of how navigation occurs during a driving task, it is interesting to note that maps with a visual balance might support the driver at different stages of the navigation task, i.e., preview, identification, confirmation, trust, and orientation, and Figures $2 \mathrm{e}$ and $2 \mathrm{f}$ illustrate maps designed at 1:6,000 that might aid drivers in these different stages of the navigation task. The high frequency of 'Direction of the next maneuver' and 'Information on general surroundings of the route' categories appears to confirm these findings.

Another result obtained from the experimental procedure showed that the second most preferred cartographic representation was the 1:3,000 scale. Drivers noted that the main advantage of maps at this scale is that they support clear identification of the direction of the next maneuver. According to driver comments, this type of map is relevant primarily for roundabouts (Figure $2 \mathrm{~g}$ and $2 \mathrm{~h}$ ). Drivers also mentioned that maps at 1:3,000 establish a proper relationship for the distance between car position and the next maneuver location compared with maps visualized at the 1:10,000 scale (Figure 3d). Two factors might explain why maps at 1:3,000 were not the most preferred. First, drivers visualized a total of approximately two blocks and half in the display, and this view reduced the information on the spatial context of the route. According to Burnett (1998), drivers require information on the general surroundings of the route to maintain and trust their orientation during the navigation task. The second factor is that drivers could not visualize the subsequent maneuvers on the route when maps were displayed at 1:3,000 (Figure 2f). These two factors were confirmed by the low use of IGS and INM categories compared with the same categories used for maps at the 1:6,000 scale (Figure. 4b).

Cartographic representations at the 1:10,000 scale also present certain advantages to drivers in different stages of the in-car navigation task. When visualizing a map at this scale, drivers not only can identify the direction of the next maneuver and the distance remaining until the junction, but they also can analyze the layout of the following maneuvers of the route and the car position. However, a certain disadvantage of maps at the 1:10,000 scale is that they contain too much information, i.e., blocks and roads are shown on the map (Figure 1d). Other disadvantages are related to legibility problems that occurred on maps at 1:10,000. As illustrated in Figure 3b, the direction arrow and car symbol are merged, and these legibility problems do not support the drivers in the preview and identification stages because they affect both the distance until the next maneuver and the car location information on the route.

Both overload of information and legibility problems might result in complex maps, and this complexity might explain the low rate of preference obtained for the 1:10,000 scale (Figure 5). According to driver comments, maps showing a high number of elements (similar to maps at 1:10,000) make it difficult to obtain information on the maneuver direction. Difficulties related to the comprehension of maneuver directions on RGNS displays could negatively affect driver performance in the task. Drivers reported that if they had to drive using a map at a 1:10,000 
scale, they either would reduce the vehicle speed or likely make more numerous 'navigational errors'.

Among the four scales used in this work, the 1:1,000 scale was the worst option adopted for RGNS maps, according to driver comments (Figure 5). First, this scale allows no time to prepare for the next maneuver. Drivers complained that maps at this scale do not aid in the navigation task because the layout of the next maneuver cannot be visualized at the beginning of the tactical task (Figure 1b). Second, drivers argued that it was confusing to hear the beep without seeing the arrow direction for the maneuver on the map. Morett et al. (2009) argued that the information communication process is more effective when different modalities, i.e., visual and auditory, are used in combination. Performing an in-car navigation task using maps at 1:1,000 scale would likely not aid drivers in answering questions such as 'Am I near the next maneuver?', 'When should I turn?' and 'What is around me?'. Large scales appear to support drivers in particular situations of the navigation task, i.e., maneuver performance (Figure 2c), but not the identification stage (Figure 1c). Thus, the lack of synchrony between visual and auditory modalities and the fact that maneuver directions cannot be visualized at the beginning of the tactical task might explain why maps at the 1:1,000 obtained the lowest rates of preference among drivers.

The results of the experimental procedure also revealed that the most frequently reported information categories were 'Direction of the next maneuver' and 'Information on general surroundings of the route'. These findings suggest that the main concern of drivers is related to the identification stage (DNM) and the trust and orientation stages (IGS). This work corroborates findings from previous research i.e., Dingues and Hulse (1993); Ross et al. (1996), Burnett (1998); May et al. (2003), Wu and Zhang (2009) and Lavie et al. (2011).

\section{Conclusions and Recommendations}

This paper presented a preliminary study on driver preference for scales used in maps for in-car route guidance and navigation systems. Four different questions were addressed in this work, and all questions were answered based on a controlled experiment performed with a group of drivers.

We concluded that driver preference for scales adopted on RGNSs maps was not related to gender, educational background, spatial ability or experience with the navigation system. Based on the evidence presented in this paper, we infer that drivers are required to clearly and quickly identify the direction of the maneuver and simultaneously receive information on the surroundings of the route to improve their spatial context in the navigation task. Therefore, the scale selected for RGNS maps should be one that supports drivers in quickly identifying those categories of information that are most important to performing a successful navigation task.

Based on the study cases, we concluded that intermediate scales, i.e., 1:6,000 and 1:3,000, were more acceptable among drivers compared with large $(1: 1,000)$ and small $(1: 10,000)$ scales. This preference occurred because the use of a map at a scale larger than 1:3,000 did not support drivers in the preview stage because they not could form a mental image of the maneuver layout. The use of a map at a scale smaller than 1:6,000 did not help the drivers in the identification stage because the maneuver's legibility was reduced on the map.

Because quantifying driver acceptance of information presented by RGNSs is a rapid and lowcost procedure, it can be concluded that subjective preference is an important measure that should be considered by designers in the process of usability evaluations for RGNS maps. Driver 
opinions not only note the problems of cartographic communication on maps, but drivers also can report what types of information they must receive from the maps for processing the in-car navigation task.

Although our results are promising for the determination of the initial performance of maps used in RGNSs, further evaluation it is still needed to determine map usability in terms of objective measures, i.e., navigational errors and visual demand, because these are measures strictly related to the performance of drivers in a navigation task. Thus, we suggest field tests or driving simulator tests in which drivers can follow the route tasks using the maps designed in this work.

\section{ACKNOWLEDGEMENTS}

This work was supported by the CNPq - Conselho Nacional de Desenvolvimento Científico e Tecnológico under Grant number 159674/2012-3. The first also author would like to thank UNESP (Sao Paulo State University) by all infrastructure provided to the research development.

\section{REFERENCES}

Burnett, Garry. "Turn right at the King's Head: Drivers' requirements for route guidance information". PhD Thesis. Loughborough University, 1998.

Burnett, Garry G., Lawson, G., Donkor, R., and Kuriyahawa, Y. "Menu hierarchies for invehicle user-interfaces: Modellingthe depth vs. breadth trade-off". Displays 34 (1): 241-249. 2013. Accessed March 28, 2015. doi.org/10.1016/j.displa.2013.07.001.

Ching-Torng, Lin., Wu, H-C., and Chien, T-Y. "Effects of e-map format and sub-windows on driving performance and glance behavior when using an in-vehicle navigation system". International Journal of Industrial Ergonomics 40(3): 330-336, 2010. Accessed April 03, 2015. doi:10.1016/j.ergon.2010.01.010.

Conover, W. John. Practical nonparametric statistics. New York: J. Wiley, 1999.

Dalton, P., Agarwal, P., Fraenkel, N., Baichoo, J., and Masry, A. "Driving with navigational instructions: Investigating user behaviour and performance". Accident Analysis and Prevention 50(2013): 298-303. Accessed April 03, 2015 doi.org/10.1016/j.aap.2012.05.002.

Dent, Borden., Torguson, J., and Hodler, T. Cartography: Thematic Map Design. Georgia: McGraw-Hill, 2009.

Dey, Anind. K. "Understanding and Using Context". Personal and Ubiquitous Computing 5(1): 4-7. 2001. Accessed April 03, 2015. doi.org/10.1007/s007790170019.

Dillemuth, Julie., K., Goldsberry, K., and Clarke, K. C. "Choosing the scale and extent of maps for navigation with mobile computing systems". Journal of Location Based Services 1(1): 46-61. 2007. Accessed March 10, 2015. doi.org/10.1080/17489720701484880.

Dingus, Thomas. A., and Melissa. C. Hulse. "Some human factors design issues and Recommendations for automobile navigation Information systems". Transportation Research Part C 1(2): 119-131, 1993.

Dogru, A. O., Duchêne, C., Van de Weghe, N., Mustière, S., and Ulugtekin, N. "Generalization Approaches for Car Navigation Systems". In Proceedings of First National Workshop on Generalization and Multiple Representations. 1-10. Turkey: Iznik, 2009. 
Ei-Wen L. Victor., Green, P. A., and Franzblau, A. "Where Do People Drive? Navigation System Use by Typical Drivers and Auto Experts". The journal of navigation 64(2011): 357373. 2011. Accessed March 10, 2015. doi:10.1017/S0373463310000561.

Green, Paul., Hoekstra, E., Williams, M., Wen, C., and George, K. "Examination of a VideotapeBased Method to Evaluate the Usability of Route Guidance and Traffic Information Systems". Technical report, University of Michigan Transportation Research Institute. 1993.

Hegarty, Mary., Richardson, A. E., Montello, D. R., Lovelace, K., and Subbiah, I. "Development of a self-report measure of environmental spatial ability". Intelligence 30(5): 425-447. 2002. Accessed March 10, 2015. doi:10.1016/S0160-2896(02)00116-2.

Iso 9241-11. "Ergonomic requirements for office work with visual display terminals (VDTs) Part 11: Guidance on usability". International Organization Standardization (ISO), Switzerland. 1998.

Kaber, B. David, Liang, Y., Zhang, Y., Rogers, M. L., and Gangakhedkar, S. "Driver performance effects of simultaneous visual and cognitive distraction and adaptation behavior". Transportation Research Part F. Elsevier 15(5): 491-501. 2012. Accessed March 10, 2015. doi.org/10.1016/j.trf.2012.05.004.

Labiale, Guy. "Visual search and preferences concerning different types of guidance displays". Behaviour \& Information Technology 20(3): 149-158. 2001. Accessed March 30, 2015. DOI: 10.1080/01449290110048025.

Lavie, Talia, Oron-Gilad, T., and Meyer, J. "Aesthetics and usability of in-vehicle navigation displays". International Journal of Human-Computer Studies 69(1-2): 80-99. 2011. Accessed March 15, 2015. doi:10.1016/j.ijhcs.2010.10.002.

Lavie, Talia, and Oron-Gilad, T. "Perceptions of electronic navigation displays". Behaviour \& Information Technology 32(8): 800-823. 2013. Accessed March 5, 2015. doi.org/10.1080/0144929X.2011.639806.

Lee, Joonhwan J., Forlizzi, J., and Hudson, S. E. "Iterative design of MOVE: A situationally appropriate vehicle navigation system". International Journal of Human-Computer Studies 66(2008): 198-215. Accessed March 5, 2015. doi:10.1016/j.ijhcs.2007.01.004.

Li, B., Zhu, K., Zhang, W., Wu, A., and Zhang, X. A comparative study of two wayfinding aids for simulated driving tasks - single-scale and dual-scale GPS aids. Behaviour \& Information Technology 33(4): 361-371. 2014. Accessed March 10, 2015. DOI: 10.1080/0144929X.2012.719032.

Liu, C. Yin. Comparative study of the effects of auditory, visual and multimodality displays on drivers' performance in advanced traveler information systems. Ergonomics 44(4): 425-442. 2001. Accessed March 2, 2015. DOI: 10.1080/00140130010011369.

Maceachren, M. Alan. How maps work: Representation, Visualization and Design. London: The Guilford Press, 1995.

Marques, S. Ana Paula, Decanini, M. M., and Pugliesi, E. A. Sistema de Navegação e Guia de Rota áudio-dinâmico com múltiplas escalas automáticas. Revista Brasileira de Cartografia 1(64): 57-68. 2012. Accessed March 2, 2015.

May, J. Andrew, Ross, T., and Bayer, S. H. Drivers' Information Requirements when Navigating in an Urban Environment. The Journal of Navigation 56(1): 89-100. 2003. Accessed March 12, 2015. DOI: $10.1017 / \mathrm{S} 0373463302002114$. 
Michon, A. John. 1985. A critical view of driver behaviour models: what do we know, what should we do?. In: Evans, L., R. S. Schwing. Human behaviour and traffic safety. New York: Plenum Press, 1985.

Morett, L. M., Bejnamin, A. C., Blalock, L. D., and Mong, H. M. “Applying multimedia learning theory to map learning and driving navigation". Transportation Research Part F 12(1): 40-49. 2009. Accessed March 2, 2015.

doi:10.1016/j.trf.2008.07.001.

Pugliesi, A. Edmur, Decanini, M. M. S., and Tachibana, V. M. "Evaluation of the Cartographic Communication Performance of a Route Guidance and Navigation System". Cartography and Geographic Information Science 36(2): 193-207. 2009. Accessed March 22, 2015. doi: $10.1559 / 152304009788188745$.

Pugliesi, A. Edmur, et al. "Métodos para Avaliação da Usabilidade de Sistemas de Navegação e Guia de Rota". Revista Brasileira de Cartografia 5(65): 571-589. 2013. Accessed April 3, 2015.

Pugliesi, A. Edmur, and Decanini, M. M. S. "Map or Turn-By-Turn: Which Modality do the Drivers Prefer for In-Car Route Guidance and Navigation Systems?". Boletim de Ciências Geodésicas 15(1): 3-15. 2009. Accessed April 3, 2015.

Ramos, M. Ana Paula, Decanini, M. M. S., and Pugliesi, E. A. "Escalas dos mapas de sistemas de guia de rota comercial". Revista Brasileira de Cartografia 1(66): 195-207. 2014a. Accessed May 13, 2015.

Ramos, M. Ana Paula, Pugliesi, E. A., Decanini, M. M. S., and Tachibana, V. M. "Estudo preliminar da preferência de cor para rota e seta de manobra em mapas de sistemas de guia de rota”. Boletim de Ciências Geodésicas 20(2): 317-333. 2014b. Accessed May 13, 2015.

Ramos, M. Ana Paula, Oliveira, R. F., Pugliesi, E. A., Decanini, M. M. S., and Tachibana, V. M. "Avaliação de erros navegacionais em sistema de navegação e guia de rota em automóvel com mapas em diferentes escalas". In XXVI Brazilian Congress of Cartography, Rio Grande do Sul, 1- 10. 2014c.

Ramos, M. Ana Paula, Pugliesi, E. A., Decanini, M. M. S., and Tachibana, V. M. "Visual demand for maps at different scales of in-route guidance and navigation system". In $11^{\text {th }}$ Symposium on Location Based Service, Austria: Vienna, 1-10. 2014d.

Ross, Trace, and, Burnett, G. "Evaluating the human-machine interface to vehicle navigation systems as an example of ubiquitous computing". International Journal of Human-Computer Studies 55(4): 661-674. 2001. Accessed May 23, 2015. doi:10.1006/ijhc.2001.0495.

Ross, Trace, Vaughan, G., Burnett, G., and May, A. HARDIE design guidelines handbook: human factors guidelines for information presentation by ATT systems Luxembourg: European Commission Host Organization. 1996.

Shea, K. S., and McMaster, B. S. Cartographic generalization in digital environment: when and how generalize. In AUTOCARTO 9, ACM/ASPRS, 56-67., EUA: Baltimore, 1992.

Slocum, Terry, McMaster, R. B., Kessler, F. C., and Howard, H. H. Thematic Cartography and Geovisualization. New Jersey: Pearson Prentice Hall, 2009.

Uang, Shiaw-Tsyr, and Hwang, S-L. Effects on driving behavior of congestion information and of scale of in-vehicle navigation systems. Transportation Research Part F 1(11): 423-438. 2003. Accessed May 15, 2015. doi:10.1016/S0968-090X(03)00003-2.

Wakabayashi, Yoshiki. Gender-related differences in the map use of in-vehicle navigation systems. In: International Cartographic Conference, Paris: France, 1-14. 2011. 
Wickens, D. Christopher, Lee, J. D., Liu, Y. and, Gordon-Becker, S. An Introduction to Human Factors Engineering. California: Pearson Prentice Hall. 2004.

Wittmann, M., Kiss, M., Gugg, P., Steffen, A., Fink, M., Pöppel, E., and Kamiya, H. "Effects of display position of a visual in-vehicle task on simulated driving". Applied Ergonomics 37(2): 187-199. 2006. Accessed May 25, 2015.doi:10.1016/j.apergo.2005.06.002.

$\mathrm{Wu}$, Anna., and X. Zhang. Identifying Proper Scales on Digital Maps for In-Vehicle Navigation Systems. In Human Computer Interaction, Germany: Berlin, 262-270. 2009.

Zhilin, Li, and Ho, A. "Design of Dynamic Map for Land Vehicle Navigation". The Cartographic Journal 41(3): 265-270. 2004. Accessed March 10, 2015. DOI: 10.1179/000870404X13896.

Recebido em Agosto de 2015.

Aceito em Outubro de 2015. 